- Most dental practices in the region were using computerised systems but many only to a limited extent. Barriers cited include lack of need, cost and a reluctance by practice staff to move away from a successful 'paper' system.

- Electronic mail would facilitate communication to other parts of the healthcare network eg for referrals, and with patients eg for making appointments.

- Internet access would enable all members of the dental team to access patient and professional resources available on-line, including CPD courses.

- There is potential for the development of 'electronic dental records' as part of a patient's 'electronic health record' enabling patient information to be shared within healthcare in general. This would be beneficial to patients and to healthcare providers.

\title{
Questionnaire survey on the use of computerisation in dental practices across the Thames Valley region
}

\author{
J. H. John, ${ }^{1}$ D. Thomas ${ }^{2}$ and D. Richards ${ }^{3}$
}

\begin{abstract}
Objectives To investigate the extent of and attitudes to computerisation in dental practices across the Thames Valley Strategic Health Authority Region.

Design Postal questionnaire survey.

Results A response rate of $88 \%$ was achieved. Most $(77 \%)$ of the practices were using computerised systems or were planning to do so soon. The main reasons for not using computers were that computerisation was not currently necessary (56\%), practice staff were reluctant to move to electronic systems (24\%), or because computer systems were perceived as too expensive (19\%). Computerised systems were used mainly for transmitting dental practice board data, or managing patient and financial records. Only $45 \%$ of practices had access to the internet and electronic mail (email). Forty-nine percent of practices thought that it was important to have access to email, $46 \%$ to the internet and $40 \%$ to NHSnet. Many practices requested training for staff in a variety of areas including managing databases and setting up web-sites.

Conclusions Despite the advantages of using computerised systems, many dental practices were only using them to a limited extent. Training and follow-up support may encourage dental practice teams to develop more positive attitudes towards computerisation and encourage them to use computers more extensively in clinical practice.
\end{abstract}

The 'NHS Dentistry: Options for Change' (OfC) ${ }^{1}$ report published in August 2002 outlined a number of changes to the delivery of dental care within the National Health Service (NHS). The report raised the need for better use of information and communication technology in dentistry to underpin these changes. A Dental IT Programme Board was subsequently convened and in October 2002 the Dental IT Strategy ${ }^{2}$ was published for consultation. The priorities and challenges for the Dental IT Strategy fit in with the overall NHS Information Strategy which aims to improve health-

${ }^{1}$ Dental Public Health Specialist, Cherwell Vale Primary Care Trust; ${ }^{2}$ Consultant in Dental Public Health, Cherwell Vale Primary Care Trust and Director of Postgraduate Dental Education, Oxford deanery; ${ }^{3}$ Consultant in Dental Public Health, Newbury Primary Care Trust Correspondence to: Dr J. H. John, Thames Valley Dental Public Health Network, c/o Oxford City Primary Care Trust, Richards Building, Old Road, Headington, Oxford OX3 7LG E-mail:jeyanthi.john@cherwellvale-pct.nhs.uk

\section{Refereed Paper}

Received 22.11.02; Accepted 27.03.03

doi:10.1038/sj.bdj.4810734

○ British Dental Journal 2003; 195: 585-590 care provision and choice within the health service. Central to the NHS strategy is the establishment of the NHSnet, to enable access to the World Wide Web and electronic mail (email) as well as facilitate secure communication between different persons and agencies within the NHS. Electronic health records (EHRs), which contain or point to all health information for each patient, will be transferred across NHSnet whenever the patient moves through the system. The Dental IT Strategy presents the case for a similar electronic dental record which will be integrated with the development of other electronic NHS records.

The proposal to include dentists in NHSnet requires dental practice teams to be conversant with computerised systems, but there is little research into the extent to which dental practices use computers. In 1997, the Dental Practice Board (DPB) carried out a survey of about 5,000 practices across the UK (64\% response rate). ${ }^{3}$ Fifty-nine per cent of respondents had computing facilities. This is a large increase from their 1991 Dental Computer Survey by MORI, which found that only 22\% of practices in England and Wales had computing facilities. ${ }^{4}$ The 1997 DPB survey found that although the majority of practices found it useful for storing patient details (90\%) and preparing and transmitting data to the DPB (80\%), only $30 \%$ of practices used the internet. In 1998, Downes ${ }^{5}$ carried out an electronic survey of 129 UK dentists. He achieved a response rate of 57\%. The majority of respondents reported that they used the internet almost every day (77\%) and most (85\%) used it primarily for electronic mail (email). In a 1999 study, Muhumuza et al. ${ }^{6}$ investigated dental practitioners' use of email, also using a selfadministered electronic questionnaire. The authors emailed questionnaires to a total of 425 dentists and Year 4 and 5 dental students on the BDA's electronic mailing list. There was a low response rate of 53\%, of which just under half was sent under 48 hours. Most respondents accessed email from home (69\%) and most (57\%) said they used it everyday. Email was used to communicate with professional bodies (72\%), communicate with colleagues about patients (41\%), order goods (34\%) and make patients' appointments at least some of the time (15\%). Both these studies had low response rates and targeted those who already used email making it difficult to draw conclusions about the general dentist population.

In a 1999 Glasgow study, 213 general medical practitioners (GMPs) and 183 general dental practitioners (GDPs) were surveyed 


\section{RESEARCH}

to assess attitudes towards integrated medical-dental patient-held records (PHR) in primary care. A response rate of 83\% for GDPs and $72 \%$ of GMPs was obtained. A notable finding was that only $21 \%$ of GDPs, compared with $85 \%$ of GMPs, had practice computers. ${ }^{7}$ We set out to investigate to what extent and for what purposes computerised systems are used in dental practices across the Thames Valley Strategic Health Authority region (counties of Berkshire, Buckinghamshire and Oxfordshire).

\section{OBJECTIVES}

1. To determine the extent of computerisation in dental practices across the Thames Valley Strategic Health Authority region.

2. To ascertain dental practice access to the internet, email and the use of practice websites.

3. To investigate attitudes to using computers in dental practice.

\section{METHODS}

A questionnaire survey was conducted amongst dentists in the Thames Valley Strategic Health Authority region. All dentists on the regularly updated lists maintained by the health authorities of Berkshire, Buckinghamshire and Oxfordshire were included. A self-administered postal questionnaire was used to collect data. This was accompanied by a letter explaining the aims of the survey and a reply-paid envelope. The main mailing was conducted in November 2001. Non-respondents were sent a reminder in March 2002. Questionnaires identical to the first were enclosed with the reminder.

The questionnaire (Fig. 1) comprised ten items. Attitudinal variables were measured using 5-point Likert-type scales. Respondents were also given an opportunity at the end of the questionnaire to make comments on any issue related to this area.

\section{Fig. 1 Dental practice computerisation questionnaire}

Please complete these questions by filling in your answer in the space provided or ticking the selected box. For questions 1 to 5 please tick as many options as apply.

Practice name

Lead dentist

1. Does your practice use any computerised systems at all? Yes $\square$ No $\square$

If yes, which of the following do you use it for?

$\square$ Managing appointments for patients

Maintaining practice accounts

$\square$ Storing patient records/notes

$\square$ Storing patients' X-rays or photographs digitally

$\square$ Submitting claims electronically to the Dental Practice Board

Dother - Please specify....

Which dental software system(s) do you use?

If you are NOT using any computerised systems at the moment, why not?

$\square$ Too expensive

$\square$ Not necessary at the moment

$\square$ Practice team reluctant to move to computerised systems

$\square$ Other - Please specify.

2. Do you have email access at the practice?

Yes $\square$ No $\square$

If yes, which of the following do you use it for?

Making patient appointments

$\square$ Sending appointment reminders to patients

$\square$ Publicising dental services available at the practice

$\square$ Personal use by practice staff

$\square$ Other - Please specify.

\section{Do you have internet access from the practice?}

Yes $\square$ No $\square$

If yes, which of the following websites do practice members access?

$\square$ Dental journals eg British Dental Journal

- Health information eg Glasgow Oral Cancer website

$\square$ Continuing Professional Development courses eg www.smile-on.com

$\square$ General Dental Council

$\square$ Medline

$\square$ NHS website $\square$ Other - Please specify

4. Does your practice have a web-site?

If yes,

Web-site address

Which of the following do you use your web-site for?

Publicising information about services available at the practice

$\square$ Providing dental health education for patients

$\square$ Advertising for new patients

$\square$ Other - Please specify

5. What sort of computer training would be useful for your practice team?

$\square$ Using E-mail

$\square$ Word-processing

Managing databases or spreadsheets (eg for patient data, accounting etc.)

$\square$ Searching for dental/health information using the Internet

$\square$ Setting up and managing web-sites

Dother - Please specify

\begin{tabular}{l|l|l|l|l|l} 
& Very important & Important & Neutral & Not important & Irrelevant \\
\hline Email & & & & & \\
\hline Internet & & & & & \\
\hline NHS net & & & & & \\
\hline
\end{tabular}

6. In your opinion, how important is it for all dental practices to be connected to the following?

7. Number of dentists in the practice

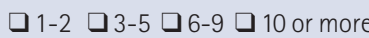

8. Is the practice

a Mainly NHS

$\square$ Mainly Private

$\square$ Mixed NHS and Private

9. Is the practice limited to a particular specialty?

$\square$ Yes - Please specify

$\square$ No

10. Any other comments (please write below and continue overleaf) 
RESEARCH

The data from the questionnaires were entered into a database using the software program Epi-Info Version 6.0 and then exported to and analysed using the statistical program SPSS (Statistical Package for the Social Sciences) for MS Windows Version 10.0. Frequencies and percentages were used to determine the distribution of responses for each variable. Percentages for each variable were based on the number of respondents for each question (denominators in the text vary according to the numbers of respondents who answered each question). Use of computerisation, access to email, access to the internet and having a practice website was cross-tabulated against size of practice (one to two dentists compared with three or more dentists).

\section{RESULTS}

Of the 356 general dental practices who were mailed, 313 (88\%) returned completed questionnaires (estimated number of dentists is 800 ). Details relating to the profile of the responding practices are illustrated in Table 1. Just over half (53\%) were small practices with one or two dentists. The majority of the practices (86\%) were not limited to any specialty. About half of the specialist practices were limited to orthodontics $(15,54 \%)$.

The majority $(241,77 \%)$ of practices reported that they used computers or were in the process of computerising (Table 2). Larger practices (three or more dentists) were significantly more likely to use computerised systems than smaller practices (84\% compared with $72 \%, P=0.01$ ). However, practices varied widely in the extent to which computers were used in practice. A majority of practices (74\%) sent information electronically to the DPB (Fig. 2). Most of the practices also used computerised systems for maintaining practice accounts (66\%), scheduling appointments (60\%) and storing patients' clinical records (59\%). A small percentage used it for storing digital radiographs (24\%), administrative tasks eg writing referral letters (16\%), and patient management eg sending recall reminders (14\%). The majority of practices used the 'TMS Arthur' system (36\%) with 'Software of Excellence' the next most commonly used system (16\%).

More than half of practices without computerised systems believed that it was not necessary to computerise at present (Table 3). About 20\% found the cost prohibitive and about 20\% reported that their practice team was reluctant to move to computerised systems. Other reasons included a belief that comput-

\section{Table 1 Profile of practices}

\begin{tabular}{lcc}
\hline & No. & $\%$ \\
& $N=313$ & \\
\hline Number of dentists & & 52.7 \\
$1-2$ & 165 & 46.6 \\
$\geq 3$ & 146 & 0.6 \\
Not stated & 2 & \\
\hline Specialised practices & & 86.3 \\
Not limited to a speciality & 270 & 7.3 \\
Limited to a speciality & 23 & 6.4 \\
Not stated & 20 &
\end{tabular}

\begin{tabular}{lcc} 
Table 2 Use of computerised systems \\
\hline & $\begin{array}{c}\text { No. } \\
(N=313)\end{array}$ & $\%$ \\
\hline Use computer systems & 241 & 77.0 \\
\hline Have access to email & 141 & 45.0 \\
Have internet access & 141 & 45.0 \\
Practice has a web-site & 69 & 22.0
\end{tabular}

erisation was time-consuming or inefficient, lack of space and a reluctance to move away from a paper system that "worked well'.

About $45 \%$ of responding practices had access to electronic mail (e-mail). More than 60\% of these practices reported that their e-mail system was used by practice staff to send and receive personal mail. A small proportion used it for making patient appointments (18\%), reminding patients about appointments (16\%), and publicising services available at the practice $(16 \%)$.

About $45 \%$ of practices had access to the internet. Most said they used it to access dental journals (61\%), continuing professional development (CPD) courses (49\%) or the General Dental Council (41\%) (Fig. 3).

Only $22 \%$ of practices had a web-site. Of these, $90 \%$ used it to publicise their services and 62\% to advertise for new patients. A smaller proportion (44\%) used it for patient education. Larger practices (three or more dentists) were more likely to have websites than smaller practices (26\% compared with $18 \%, P=0.05)$.

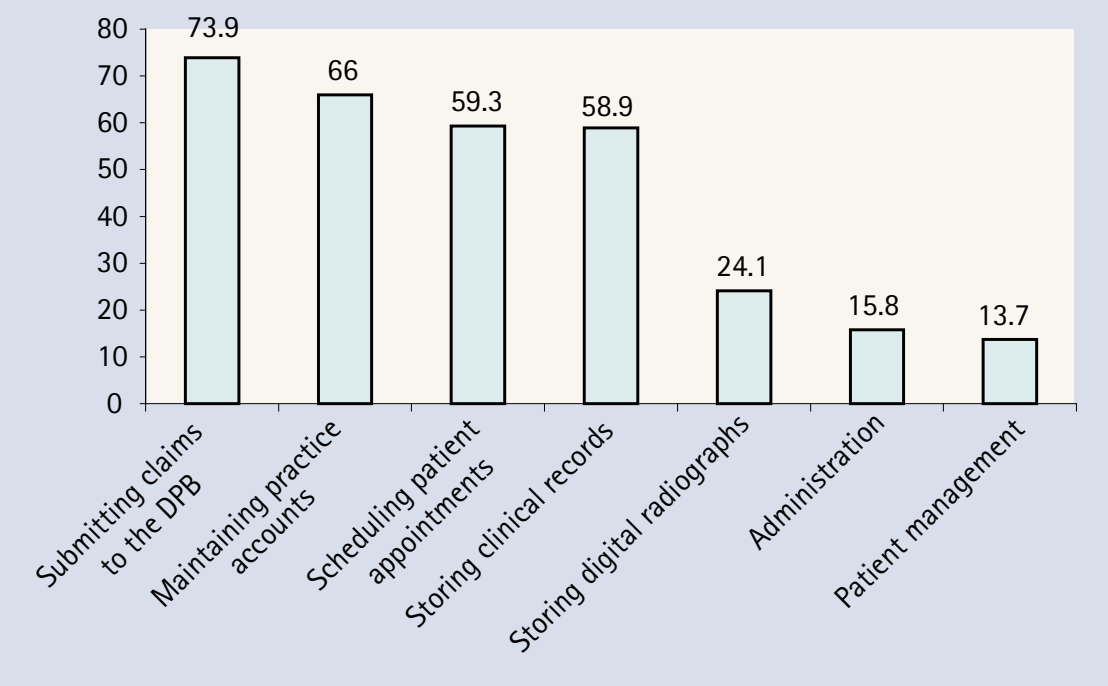




\begin{tabular}{lcc}
\multicolumn{3}{l}{ Table $\mathbf{3}$ Reasons for not using computer systems } \\
\hline & $N=72^{*}$ & $\%$ \\
\hline Not necessary at the moment & 40 & 55.6 \\
Practice team reluctant to & 17 & 23.6 \\
move to computerised systems & 14 & 19.4 \\
Too expensive & 15 & 20.8 \\
Other &
\end{tabular}

\begin{tabular}{|c|c|c|}
\hline & $N=313^{*}$ & $\%$ \\
\hline Managing databases or spreadsheets & 150 & 47.9 \\
\hline Word-processing & 142 & 45.4 \\
\hline Setting up and managing web-sites & 123 & 39.3 \\
\hline Using email & 117 & 37.4 \\
\hline Searching for dental/health information on the Web & 114 & 36.4 \\
\hline Other & 15 & 4.8 \\
\hline
\end{tabular}

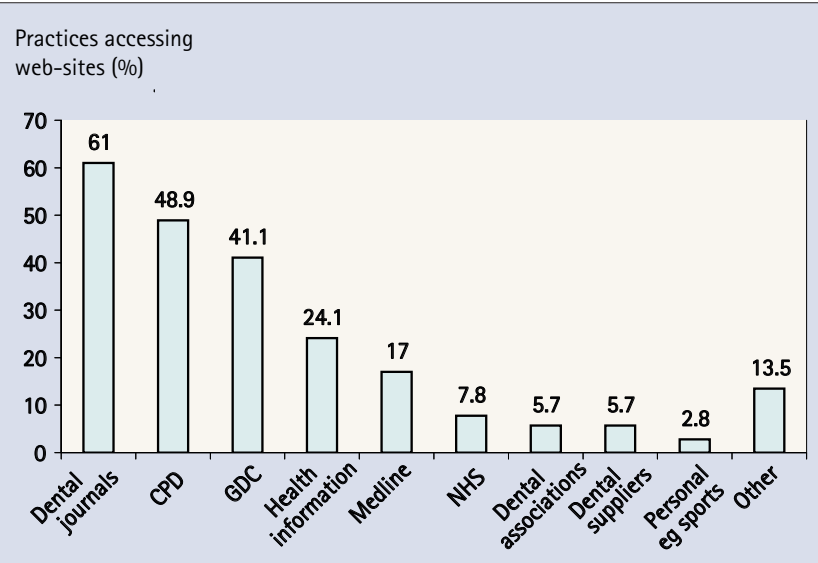

Fig. 3 Percentage of practices accessing websites

About half of responding practices thought it was very important or important for all dental practices to be connected to email (49\%), the internet (46\%) and to NHS net (40\%) (Fig. 4). About $48 \%$ wanted some kind of training for the practice team. This ranged from using email (37\%) to setting up and managing websites (39\%) (Table 4).

\section{DISCUSSION}

Most (77\%) of the dental practices who responded to our survey used computerised systems. This is consistent with the Dental IT Strategy which estimates that $75-80 \%$ of practices nationally use computerised systems for some aspects of dental practice management. This is an encouraging rise from the 59\% that was estimated from the 1997 DPB survey. ${ }^{3}$

In our survey, larger practices were significantly more likely to use computerised systems. This confirms the findings of the 1997 DPB survey which found that more than $80 \%$ of practices with six or more dentists had computing facilities compared with just under half of practices with only one dentist working at the site. ${ }^{3}$ This is not really surprising as larger practices are likely to have access to greater resources, and the larger patient base may make the use of computerised systems seem more attractive. The OfC report suggests large multi-surgery health centres for the future, which would provide a range of health services for the area including dentistry. Computerised systems would certainly be invaluable in this sort of set-up but for small or single-handed practices, connection to an electronic network would be useful to help prevent professional isolation.

There is now a drive for all health professionals, including dentists, to practice evidence-based healthcare. This requires all clinical decisions to be underpinned by up-to-date information about the best available options for each situation. With the large number of journals that are published regularly, it can be difficult for practitioners to keep abreast of current developments. Searchable bibliographic databases on the web such as the Cochrane Library (www.cochrane.org, accessible through the National Electronic Library for Health www.nelh.co.uk) and Medline (accessible via the PubMed website www.ncbi.nlm.nih.gov/PubMed), enable the user to locate the most recent publications on a wide range of topics. An oral health branch for the NeLH is under development and will eventually be available on-line to all health professionals. Many journals now have a web presence which enable subscribers to obtain access to an article, a particular issue or subscribe to the electronic edition of the journal, for example, the Lancet (www.thelancet.com). In our survey, a large proportion of the practices which were connected to the internet, used it to access dental journals indicating the importance of this aspect of internet access to clinicians. Organisations such as the Department of Health (UK) (www.doh. gov.uk), the Centre for Evidence-based Dentistry (UK) (www.ihs.ox.ac.uk/cebd) and the Centres for Disease Control and Prevention (USA) (www.cdc.gov), maintain websites with up-to-date information on a range of issues, often available at no charge. Organisations such as the British Dental Association (www.bda.org), also provide a range of resources on the web ranging from advice on clinical governance procedures to patient education leaflets. This is a valuable resource not just for dentists, but for all members of the dental practice team.

New regulations require dentists to complete a certain number of hours of continuing professional development (CPD) to stay in practice. Many clinicians, however, may have difficulties taking time out of busy surgery schedules or may have to travel large distances to get to accredited courses. This has spawned the development of on-line CPD courses. Some of these on-line courses even have a monitoring system which allow them to be accredited as verifiable CPD. Dentists can thus carry out their required $\mathrm{CPD}$ hours at a convenient time either at home or the surgery, as long as they have an internet connection. In our survey almost half the practices with internet access (49\%) used it to access CPD courses underlining the importance of this facility. To encourage local dentists to make greater use of on-line CPD, the Oxfordshire Health Authority funded a scheme, which allows all dentists in Oxfordshire to access 10 hours of free verifiable CPD through the Smile-on.com website (www.smile-on.com) using unique log-in passwords. Uptake of the scheme is currently being monitored. Since compulsory CPD may be extended to other members of the dental team in the future, on-line access to courses would be potentially beneficial to all team members working at the practice.

A big incentive for practices to establish access to the internet is the tremendous potential for promoting the practice to patients. The National Statistics Omnibus Survey from July 2001 indicates that $51 \%$ of adults in Great Britain have accessed the internet at some point. ${ }^{8}$ Between April to June 2001, 38\% of all UK households could access the internet from home. ${ }^{8}$ It is worth noting that $74 \%$ of adults who accessed the internet for personal use used it to find information about goods or services. These proportions will grow with continuing government support aimed at ensuring that "everyone in the UK who wants it will have access to the internet by 2005.9 Yet, only a small proportion of respondents in our survey had an internet presence. The internet is the ideal publicity 


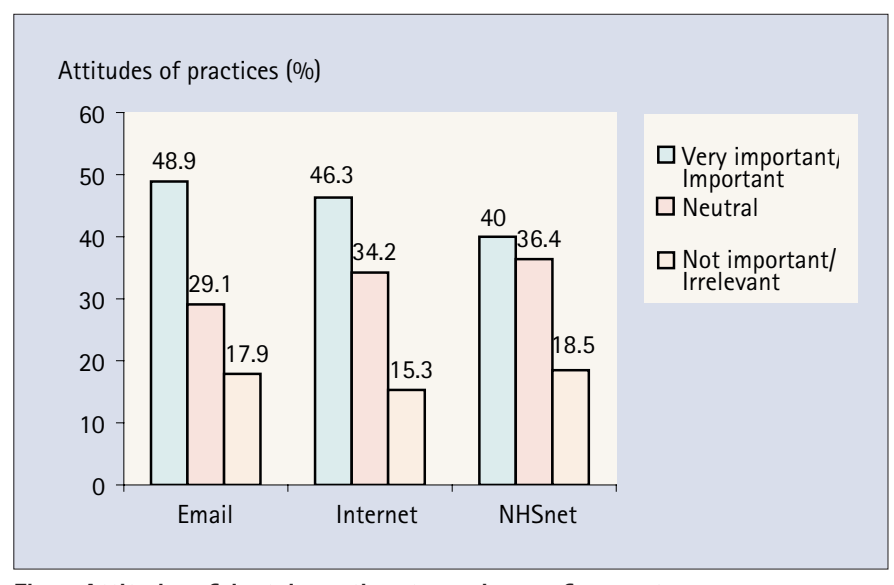

Fig. 4 Attitudes of dental practices towards use of computers

medium as there is complete control over content and design, the site can be updated as often as needed, and the pages accessed by anyone with internet access. No other medium offers this degree of flexibility or the potential to reach as many people. The Yellow Pages impose restrictions on content, information can become outdated and it may be costly. Local newsletters and newspapers have short shelf lives and may only reach a small proportion of the community. It may partly be a resistance to the practice of advertising that stops dental practices from developing their own website, but a website need not just be for advertising. It can contain information ranging from the practice location and contact details, to educational oral health information. The site can even include an option for anyone wishing to ask questions about their oral health or a clinical procedure. These questions can be dealt with by a member of staff at convenient times. This enables the practice to achieve a level of personalised communication with individual patients that would not be possible through any other means. For those without the appropriate knowledge or skills, specialist advice from various commercial sources is available to design, set up and manage the website.

In our survey, only $45 \%$ of practices had access to email, and the facility was used mainly by staff for personal communications. Communicating with patients still seems to be done primarily through the post or telephone, both of which are much more labour-intensive and time-consuming. Once email lists are established, communicating with large numbers of people can be done relatively inexpensively. Emails have the added advantage in that they can be sent or accessed at times that are convenient. Practice receptionists therefore do not need to negotiate appointment times with patients on the telephone whilst having to deal with patients waiting in the surgery. Electronic communication would also be useful for primary care trusts and other local organisations. Official information, such as circulars from the Department of Health, can be electronically cascaded down to a large number of practices quickly and relatively easily. This is particularly useful where the information is urgent. Emails could also be used to obtain opinions from colleagues and specialist practitioners which may help inform clinical decisions. Electronic referrals could be made quickly and easily through secure connections, particularly if patients' records are already in an electronic format.

Indeed the potential for sharing patient health information in the future is tremendous, not just within dentistry but within healthcare in general. A model of integrated primary medical and dental care was piloted in Glasgow in $1994 .{ }^{10}$ In the 3-year prospective study, all patient information was jointly used by a medical practice and dental practice located within the same building. Including dentistry in the medical practice's established child health surveillance and elderly-care screening pro- grammes resulted in significant increases in the proportion of 0 to 5-year-olds registering with dentists from 36\% to $68 \%$ and those aged over 75 years from $47 \%$ to $71 \%$. Joint consultations reduced the need for secondary referrals and the number of registered joint patients attending both practices increased by $90 \%$. The authors report that the joint use of patient record systems avoided discrepancies in patient information, which would have affected the quality of patient care. In the 1999 Glasgow study on medical-dental PHRs mentioned earlier, 512 patients were surveyed to investigate their attitudes to this model of care. ${ }^{7}$ Of the $408(80 \%)$ who responded, only 46\% thought the dentist needed to know their full medical history, 33\% did not and 21\% were unsure. Nine per cent thought that there were sensitive things in the medical history that they would not tell a dentist. Plus, a small proportion of patients (15\%) did not think that the doctor needed to know about healthcare treatment, such as from a dentist or other doctor. Eighty per cent of GDPs had contacted a doctor in the previous three months, and 16\% of GMPs had contacted a dentist in the same time period. The advantages of healthcare professionals working together to care for individual patients is therefore beneficial both to patients and their healthcare providers. In both these studies, the medical and dental practices which worked together were located on the same premises. However computerised records can be transferred electronically even if the two locations are geographically remote. Using NHSnet, which is equipped with electronic 'firewalls' to prevent unauthorised access, records can be transmitted quickly and easily through a secure connection to the appropriate location.

Many of the practices in our study which did not use computerised systems believed that it was not necessary at the present time. Cost and a reluctance by staff members to adopt computerised systems were also mentioned as barriers. It is understandable that practices are reluctant to move away from a tried and tested 'paper' system. Anecdotal stories of the unreliability of computer systems may discourage dental practices from investing in them, particularly if there is a continued need for paper systems as a 'back-up'. It should be noted that a large proportion of responding practices indicated that they would like training for practice team members in a variety of areas, from word-processing to setting up and managing web-sites. Training and follow-up support may encourage dental practice teams to develop more positive attitudes towards computerisation and encourage them to use computers more extensively in clinical practice. Some of the practices we surveyed would certainly include members who have access to computers at home but investigating the extent to which individual members used computers outside the practice was outside the scope of this survey. The 1997 DPB survey found that two-thirds of respondents used a computer at home, approximately two-thirds of whom used their home computers for practice management. ${ }^{3}$ It may be that dental practice team members are more conversant with computerised systems than these results indicate.

Government intervention has ensured that all healthcare organisations, will eventually be connected to NHSnet. Almost all general medical practices are now connected to NHSnet ${ }^{11}$ and there has been funding to train general practice teams to use computerised systems and incorporate them into daily clinical practice. There is recognition that this is necessary for dental practice as well. The Dental IT Strategy document ${ }^{2}$ states that 'all staff working in the NHS should have access to the European Computer Driving License (ECDL) registration, learning and testing materials by March 2003'. Information about computer software and digital technology is becoming increasingly available to primary care dental teams through the British Dental Association section meetings and other sources. 


\section{CONCLUSIONS}

The publication of the Dental IT Strategy is timely. The use of computers and the internet have revolutionised the way most people manage information and communicate. However, our survey indicates that computerised systems seem to be used only to a limited extent within dental practices and only about half of our respondents believed that internet access was important. Computerising their systems and being connected to the internet would be highly advantageous to dental practices by facilitating communication with other parts of the healthcare network, enabling dentists to communicate with and promote their services to patients and giving dental practice teams access to the wide range of patient and professional resources available on-line. Primary care dental teams need to be encouraged and supported to adopt computerised systems so as to benefit from the many advantages this would bring to their practice.
1. Department of Health. NHS Dentistry: Options for Change. London. 2002. www.doh.gov.uk/cdo/optionsforchange.

2. Department of Health. An information technology strategy for NHS Dentistry in the 21st Century. 2002. London:

www.doh.gov.uk/ipu/whatnew/dentalitstratoct2002.pdf.

3. Dental Practice Board. Dental Computer Survey 1997. Eastbourne: Dental Practice Board.

4. MORI. Dental Computer Survey 1991.2003.

5. Downes P. Survey on the use of the internet by UK dentists. 1998 www.pdownes.demon.co.uk/survey.html

6. Muhumuza R, Moles D R, Bedi R. A survey of dental practitioners on their use of, electronic mail. BrDent J1999; 186: 131-134.

7. Jones R, McConville J, Mason D, Macpherson L, Naven L, McEwen J. Attitudes towards, and utility of, an integrated medical-dental patient-held record in primary care. $\mathrm{BrJ}$ Gen Pract 1999; 49: 368-373.

8. National Statistics. Internet access - household and individuals, theme:social and welfare. 2002. www.statistics.gov.uk

9. UK online annual report 2001. Confident people - delivering universal internet access. 2001. www.e-envoy.gov.uk/ukonline/progress/anrep2001

10. Haughney M G, Devennie J C, Macpherson L M, Mason D K. Integration of primary care dental and medical services: a three-year study. Br Dent J 1998; 184: 343-347.

11. Dodson S. Where IT matters most. Primary Care (NHS magazine), 2002. 